\title{
Repression of Smad4 by miR-205 moderates TGF- $\beta$-induced epithelial-mesenchymal transition in A549 cell lines
}

\author{
YUANYUAN ZENG ${ }^{1,4^{*}}$, JIANJIE ZHU ${ }^{1,4^{*}}$, DAN SHEN $^{1 *}$, HUALONG QIN ${ }^{2}$, \\ ZHE LEI ${ }^{5}$, WEI LI ${ }^{3}$, JIAN-AN HUANG ${ }^{1,4}$ and ZEYI LIU ${ }^{1,4}$ \\ Departments of ${ }^{1}$ Respiratory Medicine, ${ }^{2}$ Cardiothoracic Surgery and ${ }^{3}$ Oncology, \\ The First Affiliated Hospital of Soochow University; ${ }^{4}$ Institute of Respiratory Diseases, \\ Soochow University; ${ }^{5}$ Suzhou Key Laboratory for Molecular Cancer Genetics, Suzhou, P.R. China
}

Received March 23, 2016; Accepted May 18, 2016

DOI: $10.3892 /$ ijo.2016.3547

\begin{abstract}
The TGF- $\beta /$ Smad signaling pathway plays important roles in cancer cell proliferation, apoptosis, differentiation, angiogenesis and epithelial-mesenchymal transition (EMT), which is the key event in the early stages of cancer metastasis and enhances the capability of cell migration and invasion. Smad4 acts as the only Co-Smad of TGF/Smad signaling pathway and plays the key role in TGF- $\beta$-mediated EMT. Nevertheless, the mRNA regulation mechanisms of Smad4 in human non-small cell lung cancer (NSCLC) remains largely unclear. Computational algorithms predicted that the 3'-UTR of Smad4 is a target of miR-205. Here, we validated that miR-205 could directly bind to 3'-UTR of Smad4 by luciferase assays. Moreover, we investigated the functional roles of miR-205 and its molecular link to Smad4 in lung cancer cells. In this study, we confirmed that overexpression of miR-205 suppressed the expression of Smad4, in turn, weakened the TGF- $\beta / \mathrm{Smad}$ signaling pathway and inhibited TGF- $\beta$ /Smad4-induced EMT, invasion and migration ultimately. Furthermore, this study shows that miR-205 can serve as a promising therapeutic target of highly aggressive NSCLC.
\end{abstract}

\section{Introduction}

Lung cancer is one of the primary causes of cancer-related death worldwide and $>80 \%$ of lung cancer patients have nonsmall cell lung cancer (NSCLC) $(1,2)$. Despite improvements in treatment modalities (such as surgical resection, chemo-

Correspondence to: Dr Zeyi Liu or Professor Jian-An Huang, Department of Respiratory Medicine, The First Affiliated Hospital of Soochow University, Suzhou, Jiangsu 215123, P.R. China

E-mail: liuzeyisuda@163.com

E-mail: huang_jian_an@yeah.net

${ }^{*}$ Contributed equally

Key words: non-small cell lung cancer, miR-205, TGF- $\beta / S m a d$ signaling pathway, Smad4, epithelial- mesenchymal transition therapy, radiotherapy, and targeted therapy), the long-term survival of NSCLC is still dismal with 5-year survival rate $>10 \%$ due to cancer relapse and metastasis $(3,4)$. Hence, good understanding of the mechanisms underlying NSCLC metastasis is very important.

The transforming growth factor $\beta$ (TGF- $\beta$ ) superfamily plays crucial roles in cell proliferation, apoptosis, differentiation, and angiogenesis $(5,6)$. In particular, its alterations significantly associated with the tumorigenic and metastatic processes of NSCLC $(7,8)$. In the canonical signaling, upon ligand stimulation, TGF- $\beta$ receptor type II (TGF- $\beta$ R 2$)$ recruits and transphosphorylates TGF- $\beta$ receptor type I (TGF- $\beta$ R1), which in turn phosphorylate Smad2 and Smad3 proteins, and these phosphorylated proteins in turn form tight protein complexes with Smad4 (also known as DPC4), and subsequently translocate to the nucleus where they interact with other transcription activator or repressors to signal downstream pathways (9). Notably, there is more and more evidence showing that TGF- $\beta$ signaling is an important inducer of epithelial-mesenchymal transition (EMT) in various cancers, including NSCLC (10-12). EMT is a critical step for morphogenesis during embryonic development and the conversion of early-stage tumors into invasive malignancies $(13,14)$, which is marked by repression of E-cadherin and induction of $\mathrm{N}$-cadherin, and Vimentin $(12,15)$. Importantly, such tumorsuppressing function of TGF- $\beta$ signaling pathway is strongly dependent on the status of Smad4 (16). Despite such functional importance, how Smad4 is regulated at transcriptional level is unclear.

MicroRNAs (miRNAs) are non-coding RNA molecules 19-24 nucleotides long that regulate gene expression at the post-transcriptional level $(17,18)$. Approximately $30 \%$ of messenger RNAs are regulated by miRNAs (19). Thus, miRNAs represent a group of important players in diverse biological and pathological processes, including tumor cell proliferation, differentiation, and survival (20-23). Recently a study showed that the expression of microRNAs appear to be tissue or tumor type-specific (24), and there is accumulating evidence showing that it could be a candidate biomarker for clinical diagnosis, including identification of cancer type or tumor subtype $(25,26)$. miR-205, which is located at lung cancer associated genomic amplification region 1q32.2. 
Dysregualtion of miR-205 was observed in many types of tumors, including lung cancer (27), moreover, miR-205 was reported to be expressed at higher level in squamous cell lung carcinoma than other types of NSCLC (25).

In this study, based on experiments in vitro and biochemical analyses, we explored the functional roles of miR-205 and its molecular link to Smad4. Our data indicate that miR-205 moderates TGF- $\beta$-induced epithelial-mesenchymal transition in NSCLC by directly targeting Smad4. Moreover, this study provides crucial molecular and cellular bases of miR-205 as one of potential clinical therapeutic targets for highly invasive NSCLC.

\section{Materials and methods}

Cell culture. Human NSCLC cells A549, obtained from the Cell Bank of the Chinese Academy of Sciences (Shanghai, China), were seeded and grown in RPMI-1640 medium (Hyclone, South Logan, UT, USA) supplemented with $10 \%$ heat-inactivated fetal bovine serum (Gibco, Carlsbad, CA, USA) and antibiotics (Invitrogen, Carlsbad, CA, USA) at the condition of $37^{\circ} \mathrm{C}$ in a humidified incubator containing $5 \% \mathrm{CO}_{2}$.

RNA extraction, $c D N A$ synthesis and quantitative real-time PCR ( $q R T-P C R)$. Total RNA of cells and tissues was extracted by adding $1.0 \mathrm{ml}$ RNAiso Plus (Takara, Osaka, Japan) according to the manufacturer's protocol. The concentration of RNA was measured using a NanoDrop 2000 (Thermo Fisher Scientific, Waltham, MA, USA). Synthesis of cDNA was carried out with reverse transcriptase M-MLV (Takara). The primers for reverse transcription and amplification of miR-205 and U6 were designed and synthesized by Guangzhou RiboBio Co. (Guangzhou, China). The sequences of qRT-PCR primers for Smad4, Snail, MMP-9 and $\beta$-actin were as follows: Smad4, forward, 5'-CAGCCATCTTG TCCACT-3'; reverse, 5'-GCTGGGGTGCTGTATGTC-3', Snail, forward, 5'-CGAAAGGCCTTCAACTGCAAAT-3'; reverse, 5'-ACTGGTACTTCTTGACATCTG-3'. MMP-9, forward, GACGATGACGAGTTGTGG; reverse, GAAGGGG AAGTGGCAG. $\beta$-actin, forward, 5'-CACAGAGCCTCGC CTTTGCC-3'; reverse, 5'-ACCCATGCCCACCATCACG-3'. qRT-PCR was performed using SYBR Premix ExTaq ${ }^{\mathrm{TM}}$ (Takara) according to the manufacturer's instructions on an ABI Step One Plus Real-Time PCR system (Applied Biosystems, Foster City, CA, USA). $\beta$-actin and U6 were respectively used as the internal controls for Smad4 and miR-205. The relative mRNA expression was measured using the $\Delta \Delta \mathrm{CT}$ method.

Western blot assay. Cells were harvested and then lysed in RIPA buffer (Cell Signaling Technology, Danvers, MA, USA) containing protease inhibitor and phosphatase inhibitor cocktail (Sigma-Aldrich, St. Louis, MO, USA). After incubation in $4^{\circ} \mathrm{C}$ for $15 \mathrm{~min}$, the total lysates were centrifuged at $12,000 \mathrm{rpm}$ for $15 \mathrm{~min}$ at $4^{\circ} \mathrm{C}$. Then the cell lysate per well was separated by $10 \%$ SDS-PAGE electrophoresis, transferred to nitrocellulose membranes (Millipore, Billerica, MA, USA), blocked with 5\% BSA in TBST buffer for $1 \mathrm{~h}$ and then immunoblotted with primary antibodies overnight at $4^{\circ} \mathrm{C}$. After 4 times washing with TBST, the membranes were further incubated with the HRP-conjugated secondary antibodies for $2 \mathrm{~h}$ at room temperature. Signal detection was performed using the ECL kit (Pierce, Rockford, IL, USA). All antibodies for western blotting including anti-Smad4; anti- $\beta$-actin and secondary antibodies were purchased from Cell Signaling Technology.

Luciferase reporter assays. Constructing a plasmid containing the Smad4 3'-UTR fused to the 3'-end of a luciferase reporter, we used psiCHECK2 dual luciferase vector (Promega, Madison, WI, USA). Briefly, a 215-bp fragment containing predicted miR-205 target site (positions 262-269) was chosen for the luciferase assay. The wild-type and mutanted fragment were directly synthesized (Genewiz, Suzhou, China), and then each subcloned into psiCHECK2 vector to generate a psiCHECK2-Smad4-3'-UTR wild-type and a psiCHECK2Smad4-3'-UTR-mutant. Subsequently, A549 cells were plated in a 24-well plate and cotransfected with wild-type or mutanted plasmid with either miR-205 mimics or miR-negative control (miR-NC) using Lipofectamine 2000 (Life Technologies). After $48 \mathrm{~h}$, cells were all harvested, and luciferase activities were measured by the Dual-Luciferase Reporter Assay kit (Promega). Each experiment was done in triplicate.

The -960 to +124 promoter region of PAI-1 was amplified by PCR with primers (forward, CGGGGTACCGCACACCC TGCAAACCTGCC and reverse, CCGCTCGAGCGATTGG CGGTTCGTCCTG). Digested with KpnI and XhoI, the acquired fragments were directly ligated into the pGL3 basic vector (Promega). pGL3 basic vector (800 ng), $800 \mathrm{ng}$ pGL3-PAI-1, 32 ng pRL-TK were co-transfected with miR-205 mimics or miR-NC using Lipofectamine 2000 (Life Technologies). Twenty-four hours later, the cells treated with/ without $5 \mathrm{ng} / \mathrm{ml}$ TGF- $\beta 1$. At last, luciferase activity of the transfected cells was determined using the Dual-Luciferase Reporter Assay kit (Promega). Each experiment was done in triplicate.

miR-205 mimics, plasmid, siRNA and cell transfection. miR-205 mimics, and matched miR-NC were synthesized by GenePharma company (Suzhou, China), The control (Si-NC) and Smad4 siRNA (Si-Smad4) were prepared as previously described (28). The target sequences of siRNA were as follows: 5'-GTACTTCATACCATGCCGA-3'. Cell transfections were performed using Lipofectamine 2000 (Invitrogen) according to the manufacturer's instructions. After 48-h transfection, the cells were collected for further experiments.

Immunocytochemistry staining. Cells were seeded into 24-well plates at a concentration of $1 \times 10^{4}$ cells/well. After treatment with/without $5 \mathrm{ng} / \mathrm{ml} \mathrm{TGF}-\beta 1$ for $48 \mathrm{~h}$, discarding the culture medium, cells were fixed with $95 \%$ alcohol and permeabilized with $0.5 \%$ Triton X-100. Five minutes later, cells were incubated with primary antibodies against E-cadherin, N-cadherin and Vimentin (1:100, BD Biosciences, San Jose, CA, USA) for $2 \mathrm{~h}$, negative controls were made with PBS instead of the primary antibodies. The second antibodies were diluted in PBS and incubated for $1 \mathrm{~h}$ at room temperature. Diaminobenzidine (DAB) was used to visualize the immunoreactivity and a light microscope was used for photography of the sections. 
A

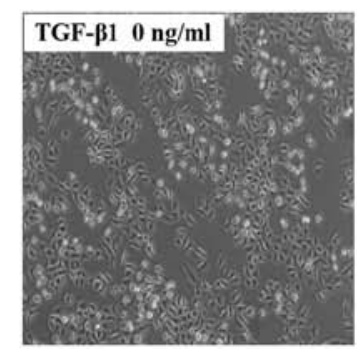

B
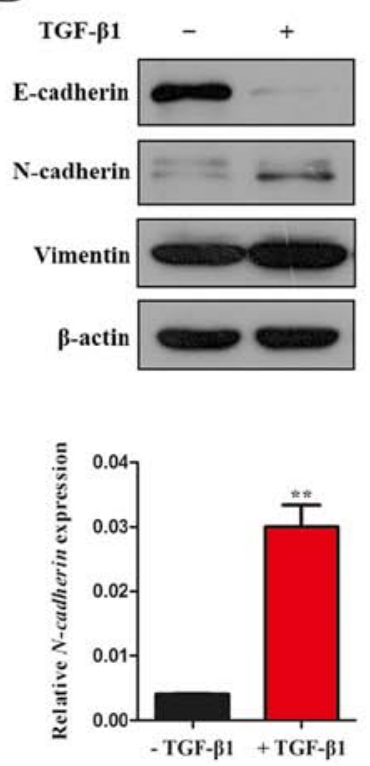
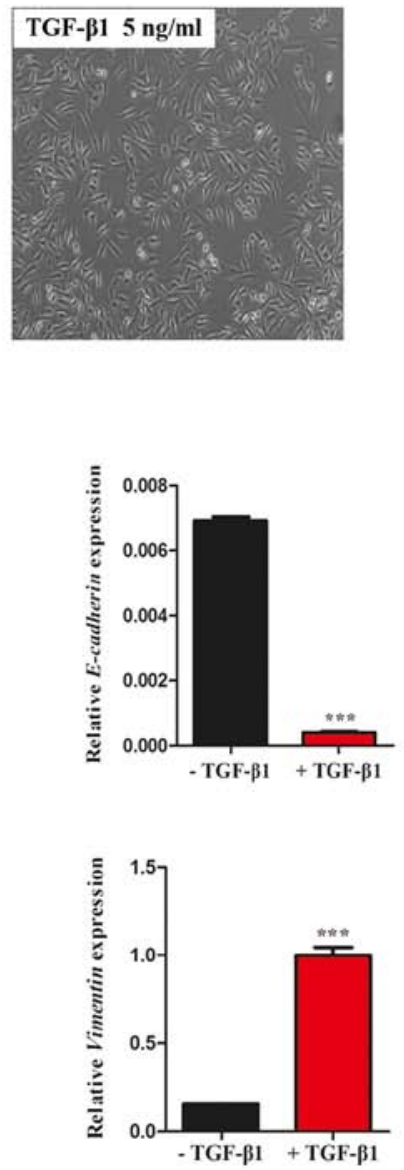

C
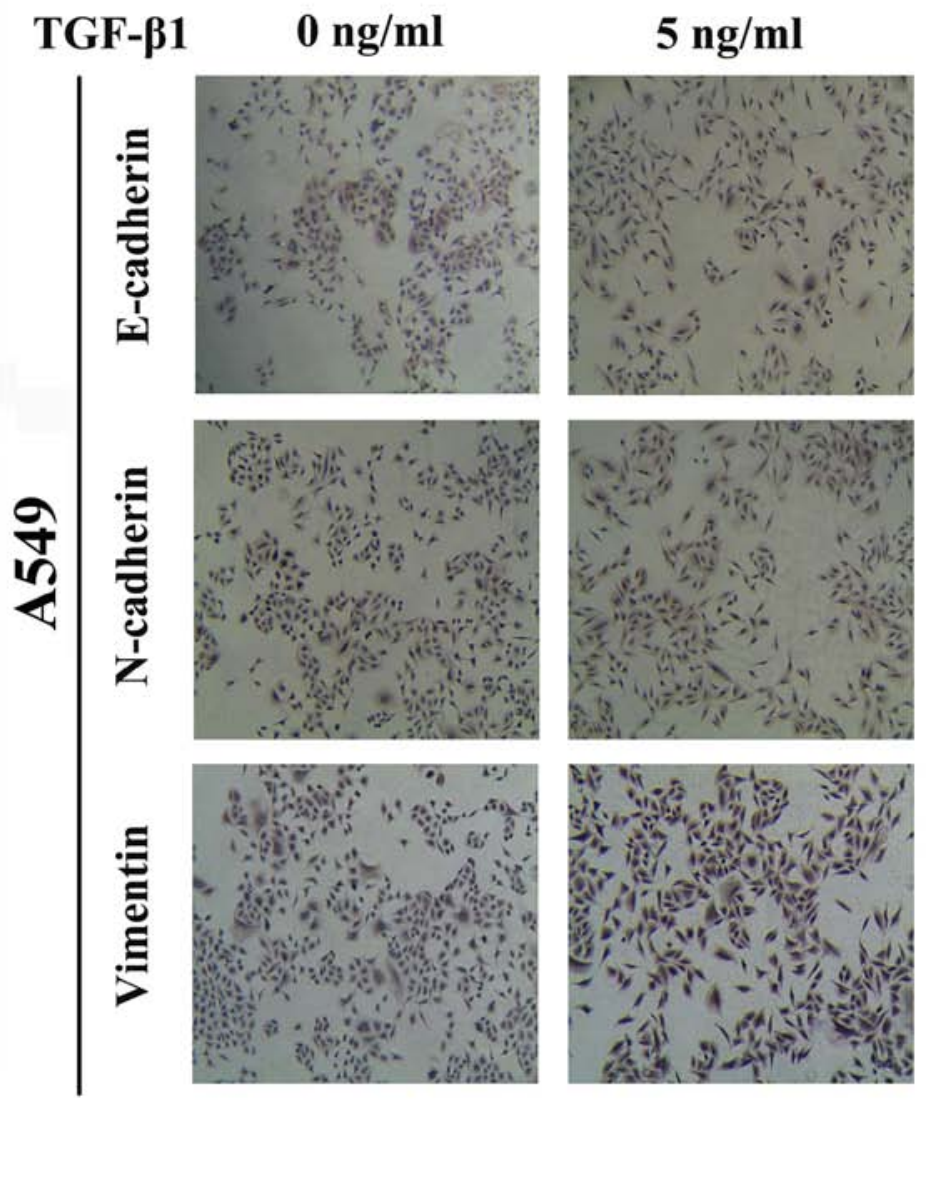

Figure 1. TGF- $\beta$ induces EMT in A549 cells. Cells induced by serum starvation for $24 \mathrm{~h}$ before treatments. (A) Presence of TGF- $\beta 1$ can induce transition of the epithelial to the mesenchymal in A549 cells. Cells were treated with $1 \%$ FBS lacking TGF- $\beta 1$ (left), and $1 \%$ FBS with 5 ng/ml TGF- $\beta 1$ (right). Cell morphology was detected at $24 \mathrm{~h}$ after TGF- $\beta 1$ stimulated and photographed by a phase microscope. (B) Altered expression of EMT hallmarkers induced by TGF- $\beta 1$. Cells were treated with or without TGF- $\beta 1$ for $24 \mathrm{~h}$; total cell lysates were extracted for western blot analyses to detect the expression of E-cadherin, N-caherin and Vimentin. $\beta$-actin was used as an internal control. (C) Immunocytochemistry staining. Cells were seeded into 24 -well plates at a concentration of $1 x 10^{4}$ cells/ well. Treatment with $5 \mathrm{ng} / \mathrm{ml}$ TGF- $\beta 1$ for $24 \mathrm{~h}$, then immunocytochemistry staining, Negative controls were made with PBS instead of the primary antibodies. Sections were examined using a light microscope. The results were expressed as the percent of positive cells. ${ }^{* *} \mathrm{P}<0.01{ }^{* * * *} \mathrm{P}<0.001$.

Wound healing assay. After $24 \mathrm{~h}$ of transfection with miR-NC and miR-205, A549 cells were seeded into a 6-well culture plate at a density of $25 \times 10^{4} /$ well. When cells reached $\sim 80-90 \%$ confluence as a monolayer, the medium was changed with $2 \mathrm{ml}$ PBS, the monolayer was gently scratched with a $10-\mu$ l pipette tip, ensuring that the tip was always vertical to the bottom of the well. The obtained gap distance equals the diameter of the end of the 10- $\mu 1$ pipette tip. After scratching, the well were washed with 1X PBS gently two times to remove the detached cells. Fresh medium was added to the well and the cells were cultured for an additional $24 \mathrm{~h}$. Photos were taken of the gap distance using a microscope and the gap distance was quantitatively evaluated using Photoshop.

Migration and invasion assays. Transwell inserts $8.0-\mu \mathrm{m}$ pores in size (Corning, NewYork, NY, USA) were used for performing cell migration and invasion assays. For migration assay, $800 \mu 1$ RPMI-1640 medium with 10\% FBS was added into each lower champer of a Transwell insert. Briefly, cells were transfected with $50 \mathrm{nM}$ miR-NC or miR-205 mimics.
Forty-eight hours post-transfection, cells were trypsinized, and then cells $\left(5 \times 10^{4}\right)$ with medium containing $1 \%$ FBS were seeded into the upper champer and incubated at $37^{\circ} \mathrm{C}$ for $24 \mathrm{~h}$ in a humidified incubator. Furtherly, the cells migrated onto the lower surface of the insert were fixed with $100 \%$ methanol for $30 \mathrm{~min}$, air-dried for $10 \mathrm{~min}$, stained with $0.1 \%$ crystal violet overnight and washed with $1 \mathrm{X}$ PBS two times. Lastly, the cells were photographed and counted. For invasion assay, the inserts were coated with Matrigel matrix (BD Science, Sparks, MD, USA) diluted in serum-free medium, then incubated at $37^{\circ} \mathrm{C}$ for $2 \mathrm{~h}$, remaining procedures were conducted similarly to migration assay. Each experiment was performed in triplicate.

Statistical analysis. Results are presented as mean \pm standard deviation (SD). Statistical significance was tested using Student's t-test and a P-value $<0.05$ was considered significant. All statistical analyses were performed using GraphPad Prism 5.0 (GraphPad, San Diego, CA, USA) and SPSS 7.0 software (SPSS, Chicago, IL, USA). 
A

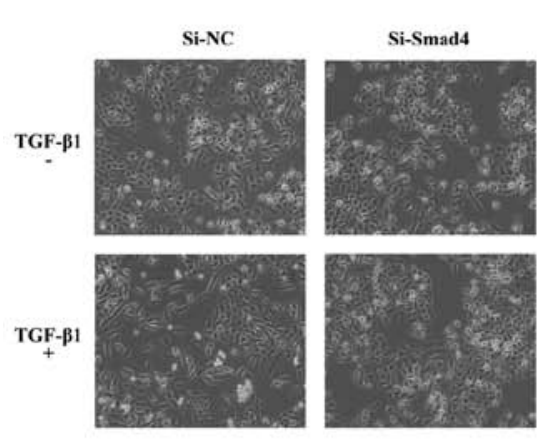

B

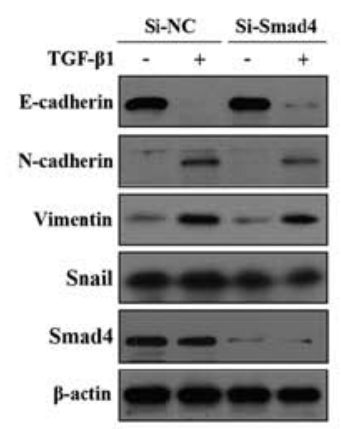

C
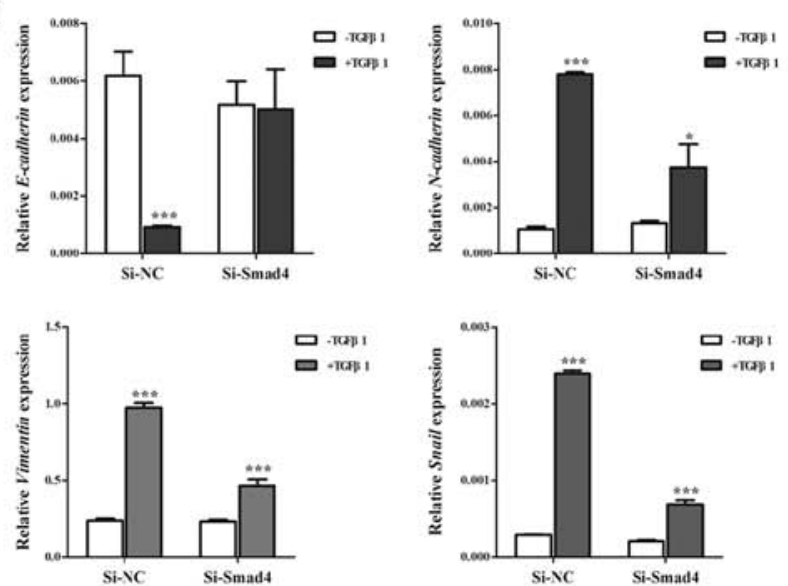

Figure 2. Silencing Smad4 inhibits TGF- $\beta$-induced EMT of NSCLC cells. (A) Smad4-silenced A549 cells were serum-starved for 24 h, cell morphology was examined at $24 \mathrm{~h}$ after TGF- $\beta 1$ treatment and photographed using a phase-contrast microscope. (B and C) Smad4-silenced A549 cells were serum-starved for $24 \mathrm{~h}$, and treated with or without TGF- $\beta 1(5 \mathrm{ng} / \mathrm{ml})$ for $24 \mathrm{~h}$. Then, E-cadherin, N-cadherin, Vimentin and Snail mRNA and protein levels were determined using qRT-PCR and western blot analyses, ${ }^{*} \mathrm{P}<0.05 ;{ }^{* * *} \mathrm{P}<0.001$.

Si-NC
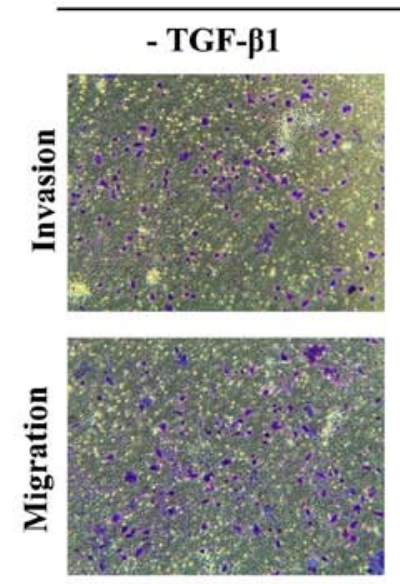

+ TGF- $\beta 1$
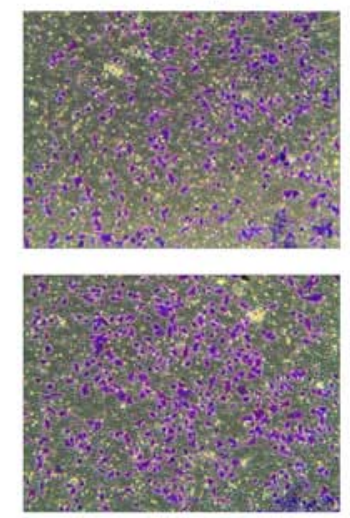

Si-Smad4
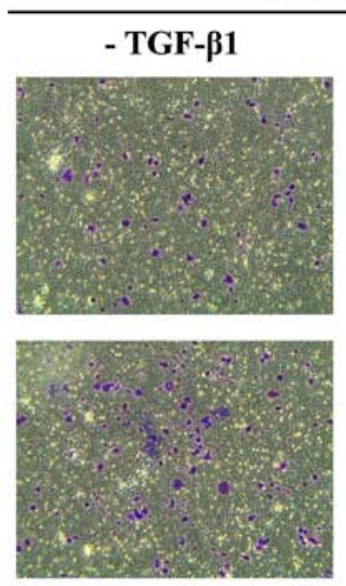

+ TGF-ß1
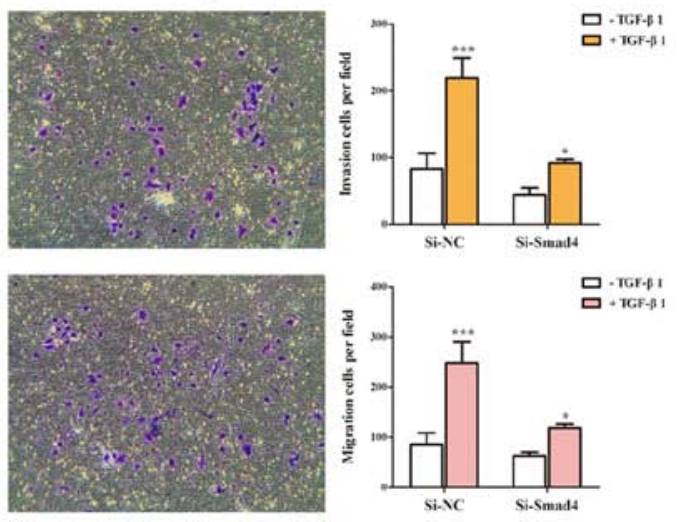

Figure 3. Silencing Smad4 inhibits TGF- $\beta$-induced invasion and migration of NSCLC cells. Smad4-silenced A549 cells were treated with TGF- $\beta 1$ (5 ng/ml) for $24 \mathrm{~h}$, and allowed to migrate through $8-\mu \mathrm{M}$ pores in Transwell inserts. Migrated cells were stained and counted in at least three microscopic fields (magnification, x100). Then, cells were treated as above and allowed to invade through Matrigel-coated membrane in Transwell inserts. Invasive cells were stained and counted under a light microscope. ${ }^{*} \mathrm{P}<0.05 ;{ }^{* * *} \mathrm{P}<0.001$.

\section{Results}

TGF- $\beta$ induces EMT in NSCLC cells. Firstly, we observed the morphological changes in A549 cells which have been widely used as a model system to study the mechanisms of carcinogenesis and tumor progression in lung cancer. In the absence of TGF- $\beta 1$, A549 cells maintained a classic epithelial morphology. On the contrary, A549 cells displayed a spindle-shape, fibroblast-like morphology after treatment with TGF- $\beta 1$ for $24 \mathrm{~h}$ (Fig. 1A). Then, we investigated the expression of epithelial marker, E-cadherin, the mesenchymal marker, $\mathrm{N}$-cadherin and Vimentin by western blot assay. In line with the morphological changes, the results showed that the expression of E-cadherin was significantly decreased and $\mathrm{N}$-cadherin and Vimentin was increased with TGF- $\beta 1$ treatment for $24 \mathrm{~h}$ in A549 cells (Fig. 1B and C). Taken together, our data indicated that TGF- $\beta 1$ was able to induce EMT in A549 cell lines.

Knockdown of Smad4 inhibits TGF- $\beta$-induced EMT, invasion and migration in NSCLC cells. Although Smad4 is the key molecule to TGF- $\beta$-induced EMT $(29,30)$, the role of Smad4 in TGF- $\beta$-induced EMT has not been studied fully. To identify this issue, we silenced Smad4 by specific SiRNA against Smad4 (Si-Smad4), and found that Si-Smad4 could remarkably decrease TGF- $\beta$-induced EMT, including morphology (Fig. 2A), and EMT markers (Fig. 2B), Si-Smad4 significantly restored E-cadherin expression and impaired $\mathrm{N}$-cadherin, Vimentin and Snail expression in the presence of TGF- $\beta 1$ (Fig. 2B and C). Then, Transwell assays showed that TGF- $\beta$-induced migratory and invasive abilities could be inhibited by knockdown of Smad4 in A549 cells (Fig. 3). 
A

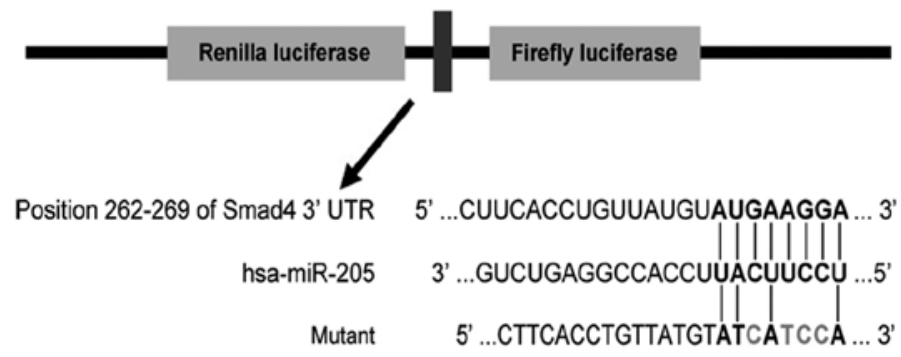

B

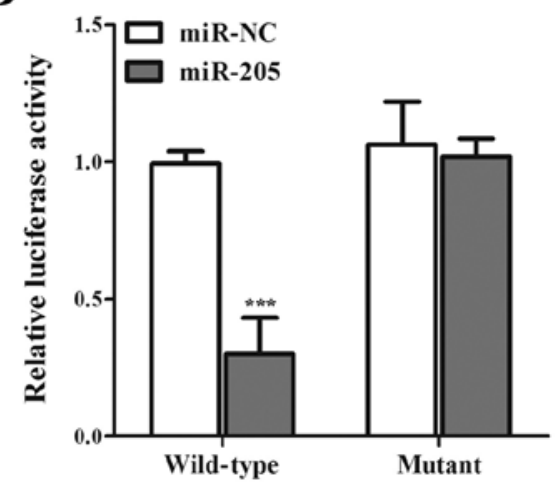

Figure 4. miR-205 regulates Smad4 expression by directly binding to 3'-UTR of Smad4. (A) Schematic drawing showing the cloning of the predicted miR-205 binding sites of Smad4 3'-UTR. Predicted duplex formation between miR-205 and the wild-type/mutant of miR-205 binding sites are indicated. (B) Luciferase activity of the wild-type or mutant Smad4 3'-UTR reporter gene in A549 cells transfected with negative control (miR-NC) or miR-205. Scrambled sequence was used as miR-NC. Relative Renilla luciferase activity is obtained after normalizing to the firefly luciferase activity. ${ }^{* * *} \mathrm{P}<0.001$.

These results suggested that TGF- $\beta$-induced EMT, invasion and migration depends on Smad4 in lung cancer cells, and reduced expression of Smad4 inhibits TGF- $\beta$ induced EMT, invasion and migration of NSCLC cells.

miR-205 directly targets Smad4 in NSCLC cells. Given the fact miRNAs can regulate various biological processes including cell proliferation by targeting proliferation-related genes (23), and Huang et al (31) predicted in silico that Smad4 was a direct target of miR-205, we consider the possibility that miR-205 can inhibit Smad4 expression by directly binding to Smad4 3'-UTR region. To confirm that Smad4 is directly regulated by miR-205, we subcloned Smad4 3'-UTR containing miR-205 binding site (wild-type/mutant type) into psiCHECK-2 vector (Fig. 4). As miR-205 is significantly downregulated in NSCLC cell lines $(32,33)$, we only transiently cotransfected the reporter construct with miR-205 mimics/miR-NC into A549 cells. Experimental results showed that miR-205 significantly inhibited the luciferase activities in cells transfected with the Smad4 3'-UTR wild-type but did not repress the luciferase activities in cells with the mutant construct (Fig. 4), moreover, the cells transfected with miR-205 mimics showed lower expression of Smad4 than miR-NC (Fig. 5A). The results suggested that miR-205 can directly target the 3'-UTR of Smad4 in NSCLC cells.

miR-205 moderates the EMT, invasion and migration induced by TGF- $\beta /$ Smad4 signal in NSCLC cell lines. As is known, the production of TGF- $\beta$ has been found increased in NSCLC cells and tissues $(34,35)$. Based on the facts that TGF- $\beta$ is one of the primary inducers of EMT in NSCLC $(36,37)$, and accumulating results showed that miR-205 can regulate key molecules and influence the signal transduction in tumor development (27), notably in EMT (12). However, Smad4 acts as the only Co-Smad of TGF/Smad signaling pathway and plays the key role in TGF- $\beta$-mediated EMT. Based on the results above, we determined whether miR-205 inhibited TGF- $\beta /$ Smad4 signal-induced EMT in A549 cell lines treated with TGF- $\beta 1$ with/without miR-205 by targeting Smad4. In our study, the cells treated with TGF- $\beta 1$ in combination with miR-205 showed higher expression of E-cadherin and lower expression of $\mathrm{N}$-cadherin and Vimentin only in the mRNA level than miR-NC (Fig. 5A-D). Then cells transfected with Smad-mediated PAI-1 reporter plasmid were stimulated with TGF- $\beta$ in the presence and absence of miR-205. As illustrated (Fig. 5E) both the basal and TGF- $\beta$-induced PAI-1 promoter activation could been attenuated significantly by miR-205. Accordingly, miR-205 can diminish TGF- $\beta$-induced enhancement in MMP-9 (Fig. 5F), which has been widely reported to promote cancer metastasis. Given the facts that TGF- $\beta$ signaling can stimulate the migration and invasion of NSCLC cells (13), we used Transwell and wounding healing assays to examine whether miR-205 could effect TGF- $\beta$-induced migration and invasion in A549 cell lines. Taken together, the results indicated that the invasion and migration function induced by TGF- $\beta /$ Smad4 signal of NSCLC cell lines (Fig. 6) could be repressed by miR-205.

\section{Discussion}

Metastasis and relapse is the major cause of death for lung cancer patients (4). EMT is a critical step in cancer metastasis, which can invert early-stage tumor into invasive malignancy (14). TGF- $\beta$-mediated signaling functions as a potent inducer of EMT which is marked by repression of E-cadherin and induction of $\mathrm{N}$-cadherin and Vimentin in cancer cells (16), contribute to progression of various cancers, including lung cancer (13).

As a Co-Smad of the Smad family, Smad4 was identified as a tumor suppressor gene in pancreatic carcinomas and initially known as 'deleted in pancreatic carcinoma locus 4 (DPC4)' (38). Although the TGF- $\beta$ pathway has been extensively studied for more than two decades, many efforts have focused on R-Smads regulation and less is known about Smad4. Recently studies showed TGF- $\beta$-responsive tumors are involved in TGF- $\beta$ / Smad4 signaling pathway showing poor differentiation and increased EMT (39). Another study showed the Smad3/Smad4 complex could bind directly to regulatory promoter region of Snail, increasing its transcription and subsequently repressing the E-cadherin expression (40). Interesting, Yang et al found that canonical TGF- $\beta / \mathrm{Smad} 4$ pathway could activate $\mathrm{CDH} 2$ 
A

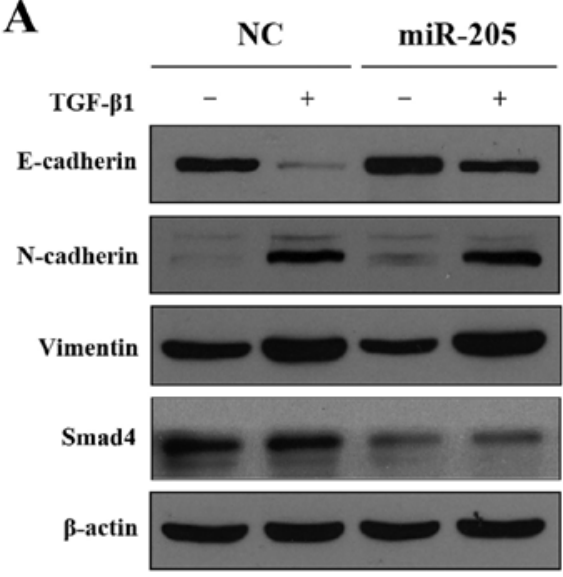

C

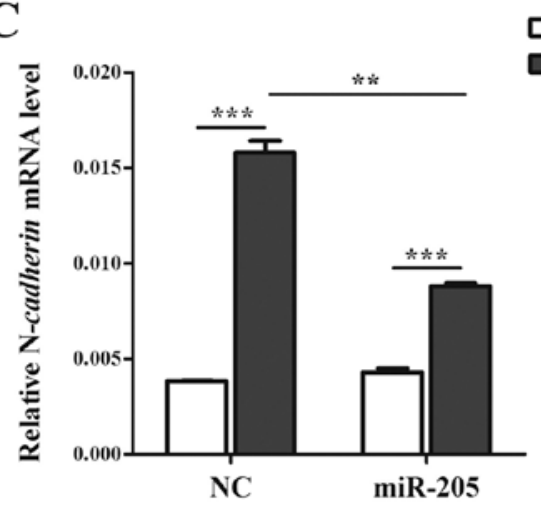

$\mathbf{E}$

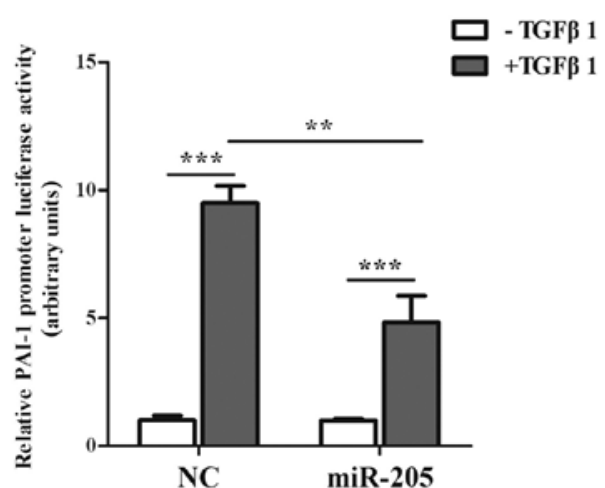

B

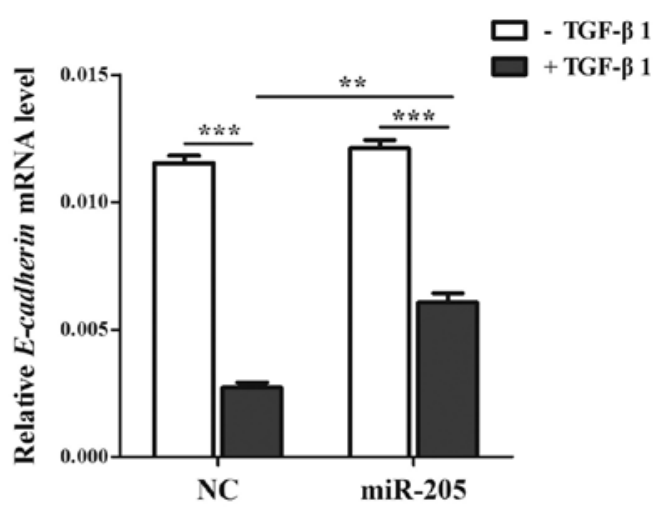

D

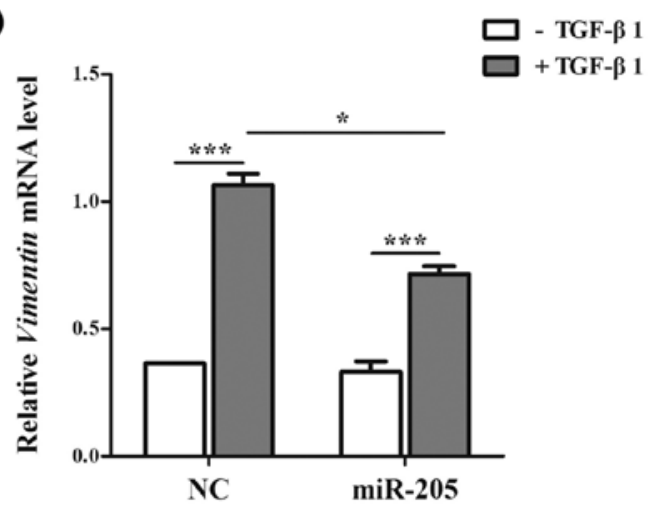

$\mathbf{F}$

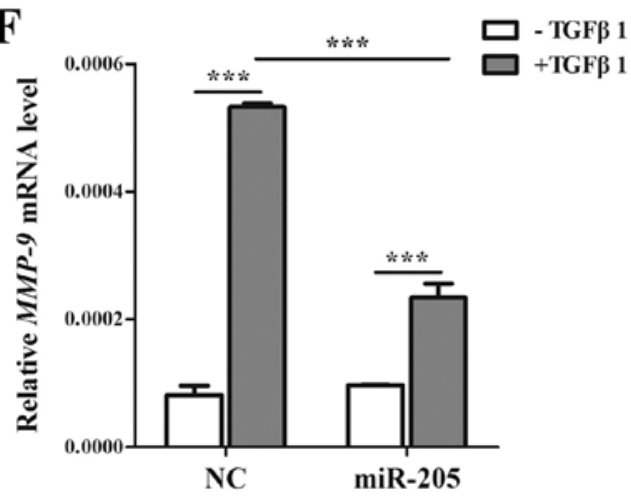

Figure 5. Overexpression of miR-205 inhibits TGF- $\beta /$ Smad4-induced EMT. (A-D) A549 cells were transfected with miR-205 mimics/miR-NC then treated with or without $5 \mathrm{ng} / \mathrm{ml}$ of TGF- $\beta 1$ for $24 \mathrm{~h}$. Cells transfected with miR-NC were used as the controls, Then, $E$-cadherin, $N$-cadherin and Vimentin mRNA and protein levels were determined using qRT-PCR and western blot analyses. (E) miR-205 attenuated TGF- $\beta$-induced PAI-1 promoter activation. Relative PAI-1 promoter activities of overexpressing miR-205 cell lines were measured by Dual-Luciferase Reporter Assay kit. Relative luciferase activity was expressed as the mean fold change from basal level \pm SD of three independent experiments. (F) $M M P-9$ mRNA expression was determined using qRT-PCR, ${ }^{*} \mathrm{P}<0.05$; ${ }^{* * *} \mathrm{P}<0.01 ;{ }^{* * *} \mathrm{P}<0.001$.

promoter to increase N-cadherin expression in NSCLC (28). These above mentioned activities improve the understanding of Smad4 serving as a tumor suppressor through its ability to inhibit epithelial cell proliferation. However, more mechanisms on TGF- $\beta$-induced EMT and its tumor-suppressive role should be elaborated and verified (41).

Since miRNAs are generally involved in the pathogenesis of cancer by directly regulating the expression of their targets at a post-transcriptional level. miR-205, which has a relationship with lung cancer associated genomic amplification region 1q32.2. Dysregualtion of miR-205 was observed in many types of tumors, including lung cancer, and it was shown to be overexpressed in different non-small cell lung carcinomas tissues, resulting in increased cell proliferation and activated angiogenesis both in vitro and in vivo through directly targeting PTEN and PHLPP2 tumor suppressor genes and subsequently activating AKT/FOXO3a and AKT/ mTOR pathways (27). Recent studies have shown altered miRNAs could affect EMT by regulated key molecules (12), including lung cancer (42). miR-205 has been found to effect EMT specially by targeting ZEB1/ZEB2 in breast cancer cells along with a decrease in E-cadherin and an increase 
A

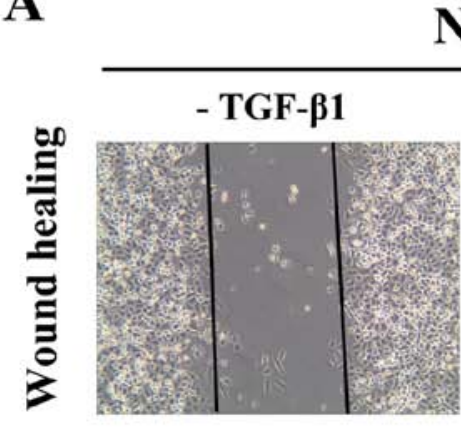

NC

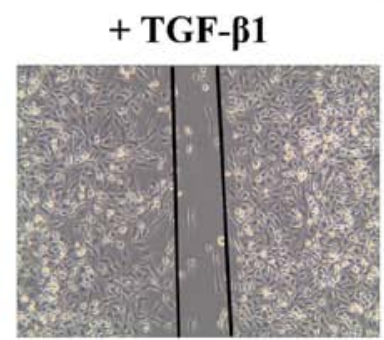

miR-205

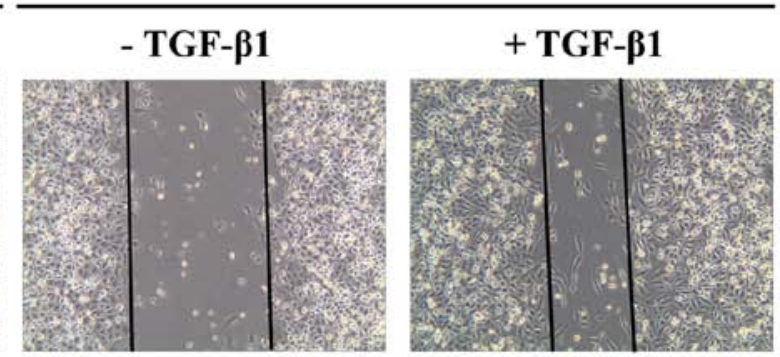

B
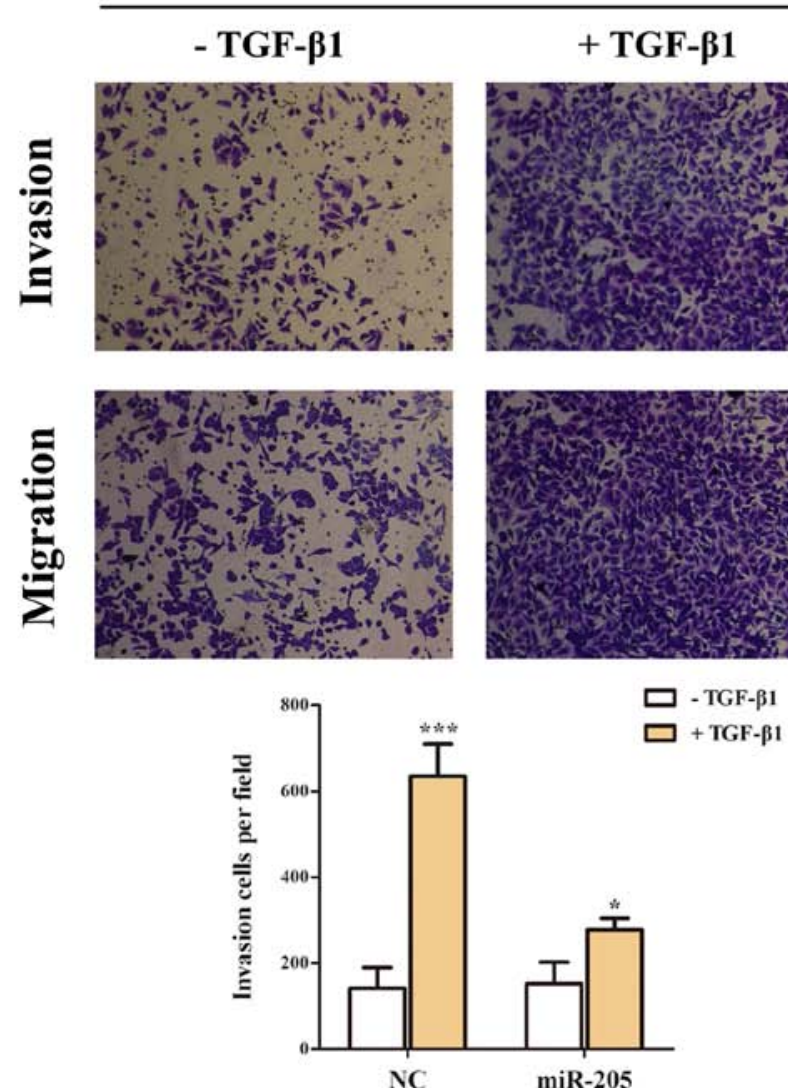

miR-205
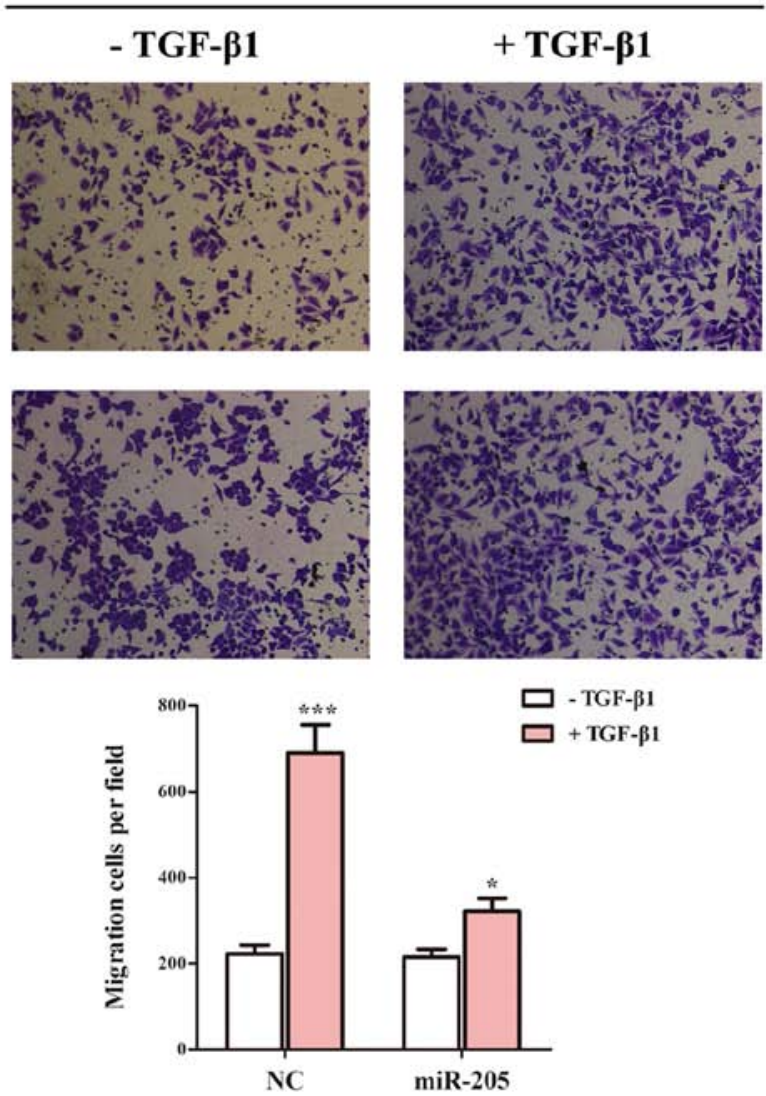

Figure 6. Overexpression of miR-205 inhibits TGF- $\beta /$ Smad4-induced invasion and migration. A549 cells were transfected with miR-205 mimics/miR-NC then treated with or without $5 \mathrm{ng} / \mathrm{ml}$ of TGF- $\beta 1$ for $24 \mathrm{~h}$. Then allowed to migrate through $8-\mu \mathrm{M}$ pores in Transwell inserts. Migrated cells were stained and counted in at least three microscopic fields (magnification, $x 100$ ). Then, cells were treated as above and allowed to invade through Matrigel-coated membrane in Transwell inserts. Invasive cells were stained and counted under a light microscope. ${ }^{*} \mathrm{P}<0.05 ;{ }^{* * *} \mathrm{P}<0.001$.

in $\mathrm{N}$-cadherin (12). On the contrary, ectopic expression of miR-205 in mesenchymal cell-initiated MET (mesenchymal to epithelial transition) with the upregulation of E-cadherin and decrease of cell migration and invasion. A recent study even found that miR-34a inhibits EMT in human cholangiocarcinoma by targeting Smad 4 through TGF- $\beta /$ Smad pathway (43). Our study shows that miR-205 suppresses the activation of TGF- $\beta / \mathrm{Smad} 4$ signal-induced EMT, invasion and migration in NSCLC cell lines by targeting Smad4.

Accumulating evidence has demonstrated that dualfunctional miR-205 may contribute to normal physiological processes, including wound healing and in development of pathological events such as cancers. The tissue-type origin of the cancer and target genes therein is thus far the only logical determinant for the dual roles of miR-205. As a tumor suppressor or oncogene, miR-205 could effectively impair or promote cancer progression through a wide variety of cellular and molecular signaling pathways; cell proliferation, programmed cell death, EMT and angiogenesis. Downregulation of miR-205 has been reported in a number of cancers, including lung cancer, Larzabal et al have also reported significant downregulation of miR-205 in non-small cell lung carcinoma compared with non-cancerous lung epithelial cells, describing it as a tumor suppressor miRNA 


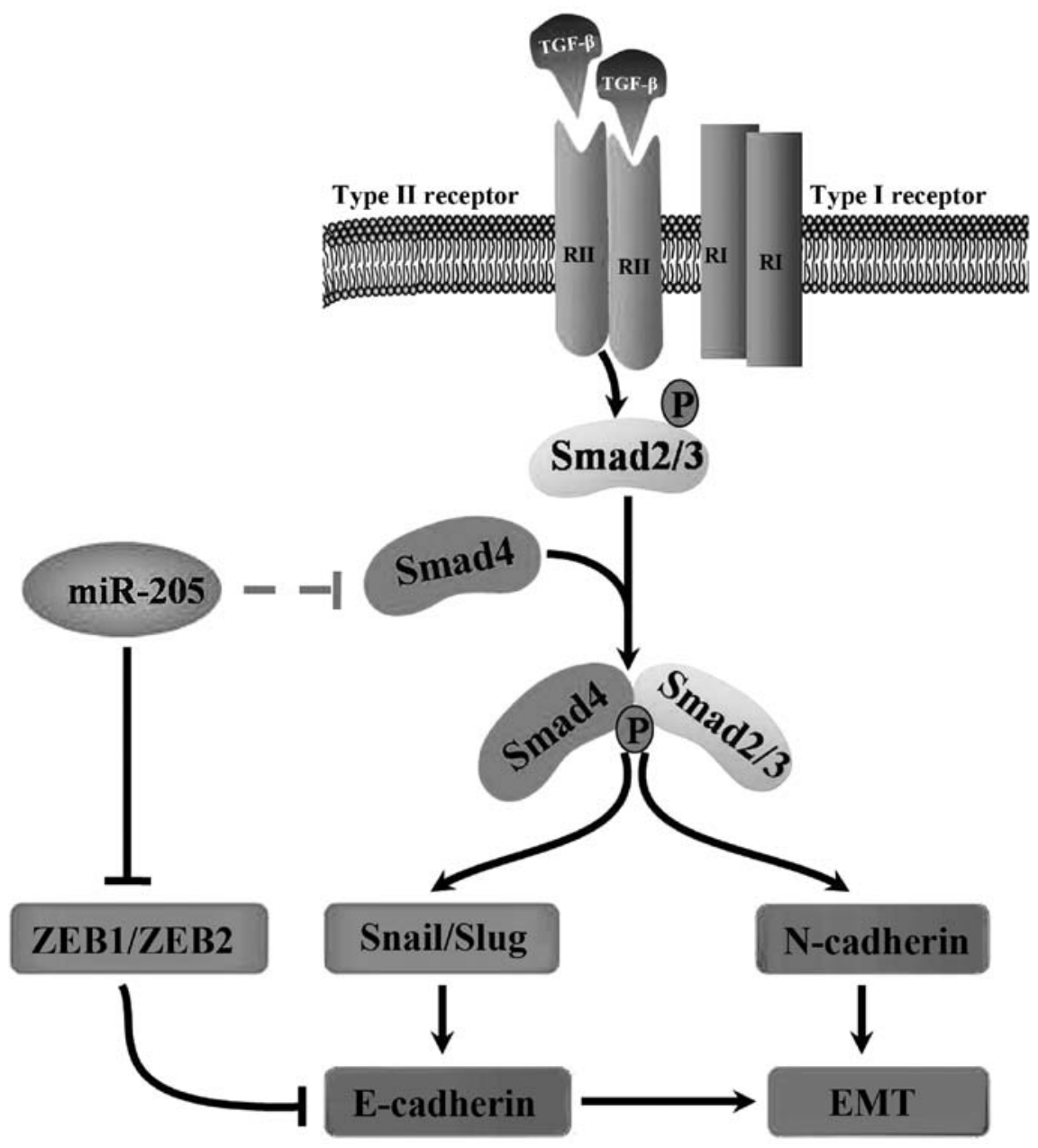

Figure 7. A proposed model of the mechanistic interaction of Smad4 and miR-205 involved in TGF- $\beta$-induced EMT.

(33). For clarification of this contradictory finding, they investigated a novel molecular signaling pathway in which miR-205 has an ability to regulate cancer cell migration and metastases by making connection between TMPRSS4 (transmembrane protease, serine 4) and integrin $\alpha 5$. TMPRSS 4 is been known as a membrane-anchored proteases implicated in cell invasion and motility. Upon knockdown of TMPRSS4, they found miR-205 was upregulated, resulting in increased E-cadherin expression, reduction of fibronectin and inhibition of epithelial-mesenchymal transition. They further found that integrin $\alpha 5$ which is involved in cell motility and invasion and also is a direct target for miR-205, was downregulated due to upregulation of miR-205. Eventually, they found a hindrance in cell migration and reduction in cell proliferation. On the other hand, miR-205 has also been detected as upregulated in lung cancer, it was shown to be overexpressed in different non-small cell lung carcinomas tissues, resulting in increased cell proliferation and activated angiogenesis both in vitro and in vivo through directly targeting PTEN and PHLPP2 tumor suppressor genes and subsequently activating AKT/FOXO3a and AKT/mTOR pathways (27). The variation of miR-205 expression may act as a diagnostic and/or prognostic biomarker tool in human cancers, with different relationships in various cancers and their subtypes. More importantly, appreciation of molecular function of miR-205 in initiation and progres- sion of cancer via targeting numerous tumor suppressor genes and oncogenes could help us to address a cancer therapeutic issue and open new avenues for gene therapy in those cancers where its tumor suppressive functions are dominant.

In conclusion, our findings demonstrate that miR-205 regulates the expression of Smad4 and impairs its functions in cells, therefore miR-205 is important for TGF- $\beta$-induced EMT, invasion and migration in NSCLC. The promising therapeutic role of miRNAs in the prevention of advanced NSCLC remains a major clinical challenge. In this study, our results strongly indicated the importance of miR-205 as a potential target in clinical therapy and demonstated that this miRNA merits further investigation as a promising gene therapy target for the treatment of NSCLC (Fig. 7). Notably, our data provide theoretical basis for study on the relationship between the miRNAs and EMT in other diseases.

\section{Acknowledgements}

This study was supported by grants from the National Natural Science Foundation of China (81201575 to Z-Y. Liu; 31270940 to J-A. Huang), Jiangsu Province Colleges and Universities Natural Science Research Foundation (12KJB310016 to Z-Y. Liu; 14KJB0017 to Z.L), Clinical Medical Center of Suzhou (Szzx201502) and Clinical Key Speciality Project of China. 


\section{References}

1. Jemal A, Bray F, Center MM, Ferlay J, Ward E and Forman D: Global cancer statistics. CA Cancer J Clin 61: 69-90, 2011.

2. Chen W, Zheng R, Baade PD, Zhang S, Zeng H, Bray F, Jemal A, Yu XQ and He J: Cancer statistics in China, 2015. CA Cancer J Clin 66: 115-132, 2016.

3. Wang T, Nelson RA, Bogardus A and Grannis FW Jr: Five-year lung cancer survival: Which advanced stage nonsmall cell lung cancer patients attain long-term survival? Cancer 116: 1518-1525, 2010.

4. Gupta GP and Massagué J: Cancer metastasis: Building a framework. Cell 127: 679-695, 2006.

5. Massagué J: TGF-beta signal transduction. Annu Rev Biochem 67: 753-791, 1998

6. Kitisin K, Saha T, Blake T, Golestaneh N, Deng M, Kim C, Tang Y, Shetty K, Mishra B and Mishra L: TGF-Beta signaling in development. Sci STKE 2007: $\mathrm{cm} 1,2007$.

7. Kim WS, Park C, Jung YS, Kim HS, Han J, Park CH, Kim K, Kim J, Shim YM and Park K: Reduced transforming growth factor-beta type II receptor (TGF-beta RII) expression in adenocarcinoma of the lung. Anticancer Res 19A: 301-306, 1999.

8. Park C, Kim WS, Choi Y, Kim H and Park K: Effects of transforming growth factor beta (TGF-beta) receptor on lung carcinogenesis. Lung Cancer 38: 143-147, 2002.

9. Shi Y and Massagué J: Mechanisms of TGF-beta signaling from cell membrane to the nucleus. Cell 113: 685-700, 2003.

10. David CJ, Huang YH, Chen M, Su J, Zou Y, Bardeesy N, Iacobuzio-Donahue CA and Massagué J: TGF- $\beta$ tumor suppression through a lethal EMT. Cell 164: 1015-1030, 2016

11. Massagué J: TGFbeta in cancer. Cell 134: 215-230, 2008.

12. Gregory PA, Bracken CP, Smith E, Bert AG, Wright JA, Roslan S, Morris M, Wyatt L, Farshid G, Lim YY, et al: An autocrine TGF-beta/ZEB/miR-200 signaling network regulates establishment and maintenance of epithelial-mesenchymal transition. Mol Biol Cell 22: 1686-1698, 2011.

13. Liu RY, Zeng Y, Lei Z, Wang L, Yang H, Liu Z, Zhao J and Zhang HT: JAK/STAT3 signaling is required for TGF- $\beta$-induced epithelial-mesenchymal transition in lung cancer cells. Int J Oncol 44: 1643-1651, 2014.

14. Kang Y and Massagué J: Epithelial-mesenchymal transitions: Twist in development and metastasis. Cell 118: 277-279, 2004.

15. Thiery JP: Epithelial-mesenchymal transitions in tumour progression. Nat Rev Cancer 2: 442-454, 2002.

16. Principe DR, Doll JA, Bauer J, Jung B, Munshi HG, Bartholin L, Pasche B, Lee C and Grippo PJ: TGF- $\beta$ : Duality of function between tumor prevention and carcinogenesis. J Natl Cancer Inst 106: djt369, 2014.

17. Mlcochova J, Faltejskova P, Nemecek R, Svoboda M and Slaby O: MicroRNAs targeting EGFR signalling pathway in colorectal cancer. J Cancer Res Clin Oncol 139: 1615-1624, 2013.

18. Schmidt A and Küppers R: Role of microRNAs in B cell leukemias and lymphomas. Curr Mol Med 14: 580-597, 2014

19. Lewis BP, Burge CB and Bartel DP: Conserved seed pairing, often flanked by adenosines, indicates that thousands of human genes are microRNA targets. Cell 120: 15-20, 2005.

20. Shi X, Zhan L, Xiao C, Lei Z, Yang H, Wang L, Zhao J and Zhang HT: miR-1238 inhibits cell proliferation by targeting LHX2 in non-small cell lung cancer. Oncotarget 6: 19043-19054, 2015.

21. Mirzamohammadi F, Papaioannou G and Kobayashi T: MicroRNAs in cartilage development, homeostasis, and disease Curr Osteoporos Rep 12: 410-419, 2014.

22. Jovanovic M and Hengartner MO: miRNAs and apoptosis: RNAs to die for. Oncogene 25: 6176-6187, 2006 .

23. Zhu J, Zeng Y, Xu C, Qin H, Lei Z, Shen D, Liu Z and Huang JA: Expression profile analysis of microRNAs and downregulated miR-486-5p and miR-30a-5p in non-small cell lung cancer Oncol Rep 34: 1779-1786, 2015.

24. Lu J, Getz G, Miska EA, Alvarez-Saavedra E, Lamb J, Peck D, Sweet-Cordero A, Ebert BL, Mak RH, Ferrando AA, et al: MicroRNA expression profiles classify human cancers. Nature 435: 834-838, 2005

25. Lebanony D, Benjamin H, Gilad S, Ezagouri M, Dov A, Ashkenazi K, Gefen N, Izraeli S, Rechavi G, Pass H, et al: Diagnostic assay based on hsa-miR-205 expression distinguishes squamous from nonsquamous non-small-cell lung carcinoma. J Clin Oncol 27: 2030-2037, 2009.
26. Markou A, Tsaroucha EG, Kaklamanis L, Fotinou M, Georgoulias V and Lianidou ES: Prognostic value of mature microRNA-21 and microRNA-205 overexpression in non-small cell lung cancer by quantitative real-time RT-PCR. Clin Chem 54: 1696-1704, 2008

27. Cai J, Fang L, Huang Y, Li R, Yuan J, Yang Y, Zhu X, Chen B, Wu J and Li M: miR-205 targets PTEN and PHLPP2 to augment AKT signaling and drive malignant phenotypes in non-small cell lung cancer. Cancer Res 73: 5402-5415, 2013

28. Yang H, Wang L, Zhao J, Chen Y, Lei Z, Liu X, Xia W, Guo L and Zhang HT: TGF- $\beta$-activated SMAD3/4 complex transcriptionally upregulates $\mathrm{N}$-cadherin expression in non-small cell lung cancer. Lung Cancer 87: 249-257, 2015.

29. Hesling C, Fattet L, Teyre G, Jury D, Gonzalo P, Lopez J, Vanbelle C, Morel AP, Gillet G, Mikaelian I, et al: Antagonistic regulation of EMT by TIF1 $\gamma$ and Smad4 in mammary epithelial cells. EMBO Rep 12: 665-672, 2011

30. Cheng H, Fertig EJ, Ozawa H, Hatakeyama H, Howard JD, Perez J, Considine M, Thakar M, Ranaweera R, Krigsfeld G, et al: Decreased SMAD4 expression is associated with induction of epithelial-to-mesenchymal transition and cetuximab resistance in head and neck squamous cell carcinoma. Cancer Biol Ther 16: 1252-1258, 2015.

31. Huang W, Jin Y, Yuan Y, Bai C, Wu Y,Zhu H and Lu S: Validation and target gene screening of hsa-miR-205 in lung squamous cell carcinoma. Chin Med J (Engl) 127: 272-278, 2014

32. Du L, Schageman JJ, Irnov, Girard L, Hammond SM, Minna JD, Gazdar AF and Pertsemlidis A: MicroRNA expression distinguishes SCLC from NSCLC lung tumor cells and suggests a possible pathological relationship between SCLCs and NSCLCs. J Exp Clin Cancer Res 29: 75, 2010.

33. Larzabal L, de Aberasturi AL, Redrado M, Rueda P, Rodriguez MJ, Bodegas ME, Montuenga LM and Calvo A: TMPRSS4 regulates levels of integrin $\alpha 5$ in NSCLC through miR-205 activity to promote metastasis. Br J Cancer 110: 764-774, 2014

34. Asselin-Paturel C, Echchakir H, Carayol G, Gay F, Opolon P, Grunenwald D, Chouaib S and Mami-Chouaib F: Quantitative analysis of Th1, Th2 and TGF-beta1 cytokine expression in tumor, TIL and PBL of non-small cell lung cancer patients. Int J Cancer 77: 7-12, 1998.

35. Bennett WP, el-Deiry WS, Rush WL, Guinee DG Jr, Freedman AN, Caporaso NE, Welsh JA, Jones RT, Borkowski A, Travis WD, et al: p21waf1/cip1 and transforming growth factor beta 1 protein expression correlate with survival in non-small cell lung cancer. Clin Cancer Res 4: 1499-1506, 1998.

36. Akhurst RJ and Balmain A: Genetic events and the role of TGF beta in epithelial tumour progression. J Pathol 187: 82-90, 1999.

37. Han G, Lu SL, Li AG, He W, Corless CL, Kulesz-Martin M and Wang XJ: Distinct mechanisms of TGF-beta1-mediated epithelial-to-mesenchymal transition and metastasis during skin carcinogenesis. J Clin Invest 115: 1714-1723, 2005.

38. Hahn SA, Schutte M, Hoque AT, Moskaluk CA, da Costa LT, Rozenblum E, Weinstein CL, Fischer A, Yeo CJ, Hruban RH, et al: DPC4, a candidate tumor suppressor gene at human chromosome 18q21.1. Science 271: 350-353, 1996.

39. Bardeesy N, Cheng KH, Berger JH, Chu GC, Pahler J, Olson P, Hezel AF, Horner J, Lauwers GY, Hanahan D, et al: Smad4 is dispensable for normal pancreas development yet critical in progression and tumor biology of pancreas cancer. Genes Dev 20: $3130-3146,2006$.

40. Vincent T, Neve EP, Johnson JR, Kukalev A, Rojo F, Albanell J, Pietras K, Virtanen I, Philipson L, Leopold PL, et al: A SNAIL1SMAD3/4 transcriptional repressor complex promotes TGF-beta mediated epithelial-mesenchymal transition. Nat Cell Biol 11: 943-950, 2009.

41. Katsuno Y, Lamouille $S$ and Derynck R: TGF- $\beta$ signaling and epithelial-mesenchymal transition in cancer progression. Curr Opin Oncol 25: 76-84, 2013.

42. Kumarswamy R, Mudduluru G,CeppiP, Muppala S, Kozlowski M, Niklinski J, Papotti M and Allgayer H: MicroRNA-30a inhibits epithelial-to-mesenchymal transition by targeting Snail and is downregulated in non-small cell lung cancer. Int J Cancer 130: 2044-2053, 2012

43. Qiao P, Li G, Bi W, Yang L, Yao L and Wu D: microRNA-34a inhibits epithelial mesenchymal transition in human cholangiocarcinoma by targeting Smad4 through transforming growth factor-beta/Smad pathway. BMC Cancer 15: 469, 2015. 